\title{
The Effect of Stricter Capital Regulation on Banks' Risk-Taking Theory and Evidence
}

\author{
Lundtofte, Frederik; Nielsen, Caren Yinxia
}

Document Version

Accepted author manuscript

Published in:

European Financial Management

DOI:

10.1111/eufm.12205

Publication date:

2019

\section{License \\ Unspecified}

Citation for published version (APA):

Lundtofte, F., \& Nielsen, C. Y. (2019). The Effect of Stricter Capital Regulation on Banks' Risk-Taking: Theory and Evidence. European Financial Management, 25(5), 1229-1248. https://doi.org/10.1111/eufm.12205

Link to publication in CBS Research Portal

\section{General rights}

Copyright and moral rights for the publications made accessible in the public portal are retained by the authors and/or other copyright owners and it is a condition of accessing publications that users recognise and abide by the legal requirements associated with these rights.

Take down policy

If you believe that this document breaches copyright please contact us (research.lib@cbs.dk) providing details, and we will remove access to the work immediately and investigate your claim. 


\section{The Effect of Stricter Capital Regulation on Banks' Risk- Taking: Theory and Evidence}

\section{Frederik Lundtofte and Caren Yinxia Nielsen}

Journal article (Accepted manuscript*)

\section{Please cite this article as:}

Lundtofte, F., \& Nielsen, С. Y. (2018). The Effect of Stricter Capital Regulation on Banks' Risk-Taking: Theory and Evidence. European Financial Management. https://doi.org/10.11l1/eufm.12205

This is the peer reviewed version of the article, which has been published in final form at DOI:

https://doi.org/10.1111/eufm.12205

This article may be used for non-commercial purposes in accordance with

Wiley Terms and Conditions for Self-Archiving

* This version of the article has been accepted for publication and undergone full peer review but has not been through the copyediting, typesetting, pagination and proofreading process, which may lead to differences between this version and the publisher's final version AKA Version of Record. 


\title{
Original Article
}

\section{The Effect of Stricter Capital Regulation on Banks' Risk-Taking: Theory and Evidence*}

\author{
Frederik Lundtofte ${ }^{\dagger}$, Caren Yinxia Nielsen
}

*The paper was previously circulated under the title "Banks' credit-portfolio choices and risk-based capital regulation." The authors would like to thank the editor (John Doukas), an anonymous referee, Giampaolo Gabbi, Jungsuk Han, Xunhua Su, seminar participants at the University of Southern Denmark, and participants at the 2014 IFABS Conference (Lisbon), the 2014 FMA Asia Conference (Tokyo), the 2014 Swedish House of Finance Workshop (Stockholm) and the 2016 FMA Europe Conference (Helsinki) for their comments and suggestions. Special thanks go to Hans Byström for valuable advice. The usual disclaimer applies. Jan Wallanders and Tom Hedelius Stiftelse, and Tore Browaldhs Stiftelse, and the sponsors of the project "Nordic Finance and the Good Society" at the Center for Corporate Governance at Copenhagen Business School are gratefully acknowledged for financing this research.

†Department of Economics and Knut Wicksell Centre for Financial Studies, Lund University, P.O. Box 7082, S-220 07 Lund, Sweden. Phone: +46 46222 8996. Fax: +46 46222 4118. E-mail: frederik.lundtofte@nek.lu.se

Center for Corporate Governance, Department of Accounting, Copenhagen Business School, Porcelænshaven 24A, DK-2000 Frederiksberg, Denmark; Guest researcher at Knut Wicksell Centre for Financial Studies, Lund, Sweden. Phone: +45 38152694. E-mail: cyn.ccg@cbs.dk

This article has been accepted for publication and undergone full peer review but has not been through the copyediting, typesetting, pagination and proofreading process, which may lead to differences between this version and the Version of Record. Please cite this article as doi:[10.1111/eufm.12205]

This article is protected by copyright. All rights reserved. 


\begin{abstract}
A simple portfolio choice model shows that, when a bank's capital is constrained by regulation, regulatory cost (risk weightings) alters the risk and value calculations for the bank's assets. In particular, we find that banks may respond to stricter regulation by increasing the share of high-risk assets. Our empirical results show that U.S. banks responded to the implementation of the stricter Basel II regulations by increasing the share of high-risk assets in the risky part of their portfolios.
\end{abstract}

Keywords: Banks; asset risk; credit risk; portfolio choice; risk-based capital regulation JEL classifications: G11; G18; G21; G28 


\section{Introduction}

The recent financial crisis, especially the sub-prime mortgage crisis, has placed a sharp spotlight on banks' risk taking. In the media, banks are often blamed for shrugging off risk concerns while pursuing higher earnings for example through high leverage or through granting loans with high credit risk. Indeed, in a model with just enough frictions for banks to have a meaningful role in producing socially valuable liquid claims, DeAngelo and Stulz (2015) find that banks will optimally be highly leveraged. However, the concern is that this type of behavior on part of the banks will leave the financial system vulnerable to economy-wide shocks. Regulatory frameworks, such as the Basel Accords ${ }^{1}$ have been put in place to counteract such tendencies among banks, initially by putting an upper limit on banks' risk-taking and altering their cost-benefit analyses.

Since a simple flat ratio of capital to asset might incentivize banks to hold more high-risk assets (see, e.g., Koehn and Santomero, 1980; Kim and Santomero, 1988), regulators have been refining capital regulation to match the actual risk of banks' assets. Yet, Basel II has been questioned for exacerbating procyclicality of banks' lending (see, e.g., Repullo and Suarez, 2013; Behn et al., 2016). In response to this type of criticism, Basel III adds a capital preservation buffer and a countercyclical buffer, and Basel IV emphasizes the calculation of the risk-weighted assets ${ }^{2}$ and reconciles the internal ratings-based approach with the standardized approach. In the US, regulators have also

\footnotetext{
${ }^{1}$ The Basel Accords are the supervision accords for banks promulgated by the Basel Committee on Banking Supervision. This study limits its focus to the aspects of the Accords that address capital adequacy, which is at the center of the Accords.

${ }^{2}$ To value the overall risk of a bank's assets, the Basel Accords use total risk-weighted assets, where a higher weight is assigned to assets with higher risk. Under Basel I and the standard approach of Basel II, there are four broad categories of risk: $0 \%, 20 \%, 50 \%$, and $100 \%$ risk weightings. The risk under Basel I is mainly credit risk. To determine capital adequacy, the Basel Accords use a risk-based capital ratio: the ratio of total regulatory capital to total risk-weighted assets. Under Basel I (1998) and II (2004), a bank has to reserve total capital equal to at least $8 \%$ of the value of the bank's total risk-weighted assets; under Basel III (2010), a bank has to hold additional conservation and countercyclical buffers.
} 
maintained a flat leverage ratio since 1981 (Volcker, 1987; Deloitte, 2014). More recently, they have introduced a supplementary leverage ratio for the very largest banks, which takes off-balance sheet items into account. ${ }^{3}$

How do individual banks navigate in a landscape of cycles of credit yields and risk such as during the pre-crisis surge in yields in the sub-prime markets or the credit shocks induced by the failure of Lehman Brothers, with simultaneous changes in capital regulation? For instance, if a bank faces increasing default probabilities and default correlations among its clients, how does it reassess the credit risks of existing and new potential assets and decide on a reallocation, while also facing a more stringent capital regulation? To answer these questions, we revisit the literature on banks' asset portfolio choices (Koehn and Santomero, 1980; Kim and Santomero, 1988; Rochet, 1992; Furfine, 2001; Milne, 2002) with a special focus on credit risk.

First, we look into US banks ${ }^{4}$ total assets ${ }^{5}$ with different levels of risk, defined by the risk weightings under the Basel Accords. Figures 1a and 1b display the sums of the assets with certain risk weightings for all U.S. banks from the fourth quarter of 2002 to the fourth quarter of 2014. According to Figure 1a, there is a distinct increase in the amount of assets with the highest risk (100\% risk weighting), although the trend for its proportion of the total is not obvious (Figure $1 \mathrm{~b}$ ). Figure 2 shows banks' allocation among risky assets whose risk weightings are nonzero. Prior to the financial crisis, there is an increase in the proportion allocated to the riskiest assets. Since it takes some time to adjust long-term assets, this proportion declines sometime after the onset of the

\footnotetext{
${ }^{3}$ The supplementary leverage ratio was finalized in September, 2014 (Deloitte, 2014).

${ }^{4} \mathrm{Here}$, and in the rest of the paper, we refer to stand-alone bank-holding companies and stand-alone commercial banks as "banks". With this strict definition, we avoid considering potentially misleading data emerging from regulatory arbitrage within financial conglomerates.

${ }^{5}$ For assets with $0 \%$ risk weight, total amount for each bank is not available in CapitalIQ, which is the data source of our empirical tests. Here, we extract the data on assets within different risk categories for the banks, the same as in our sample in the empirical tests, from the regulatory reports available from the databases of the Federal Reserve.
} 


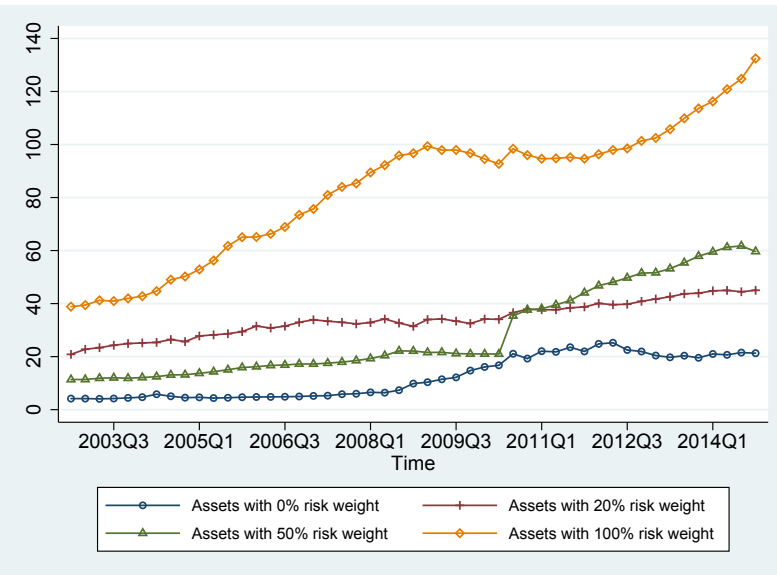

(a) Allocation to different asset classes

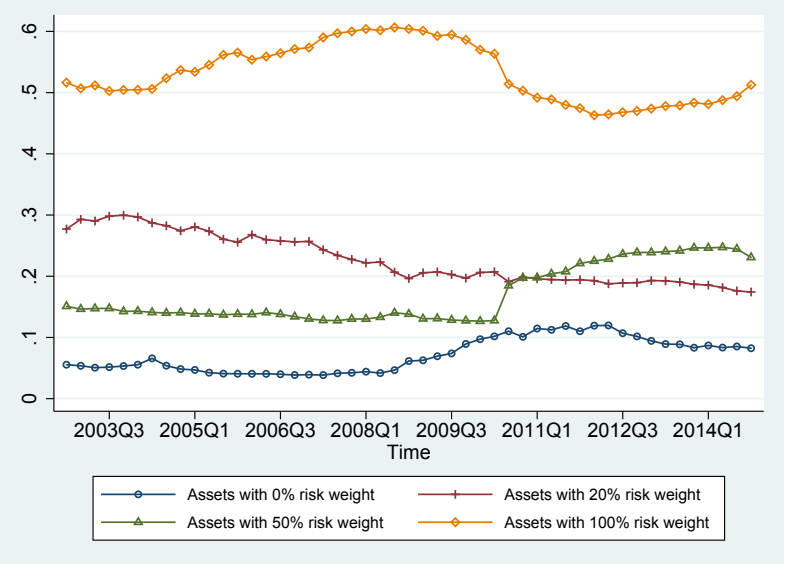

(b) Allocation to different asset classes in proportion

Figure 1: Banks' allocation to assets with different risk weightings

This figure displays total asset amounts within different risk categories of all the stand-alone banks and bank-holding companies in the U.S., measured in trillions of dollars in Figure 1a and in proportions to total amounts in Figure 1b.

financial crisis, but when it declines, we see a sharp decline. However, towards the end of the sample period, the banks' risk-taking starts to increase again. Combining Figures 1 and 2 with common knowledge regarding business cycles, we see that banks' risk-taking tends to increase during upturns, i.e., they exhibit procyclicality, a stylized fact that has been established in the previous literature (e.g., Berger and Udell, 2004; Santos and Winton, 2008; Murfin, 2012). Recent bank regulation (in particular Basel III \& IV) intends to counteract this phenomenon. ${ }^{6}$

Basel II was revised to closely match banks' actual asset risk and we can also regard it as a tightened regulation compared to Basel I, since there is less room for regulatory arbitrage. Moreover, since 1981, US banks are also subject to a traditional leverage ratio requirement (Volcker, 1987). However, back-of-the-envelope calculations suggest that the risk-weighted capital requirements of Basel I \& II are a more serious concern for the banks than the traditional leverage ratio: out of the 597 banks in our sample, there is only one bank that only violates a leverage ratio requirement of

\footnotetext{
${ }^{6}$ Notice that the figures reflect mainly credit risk before the second quarter in 2008, when Basel II took effect.
} 


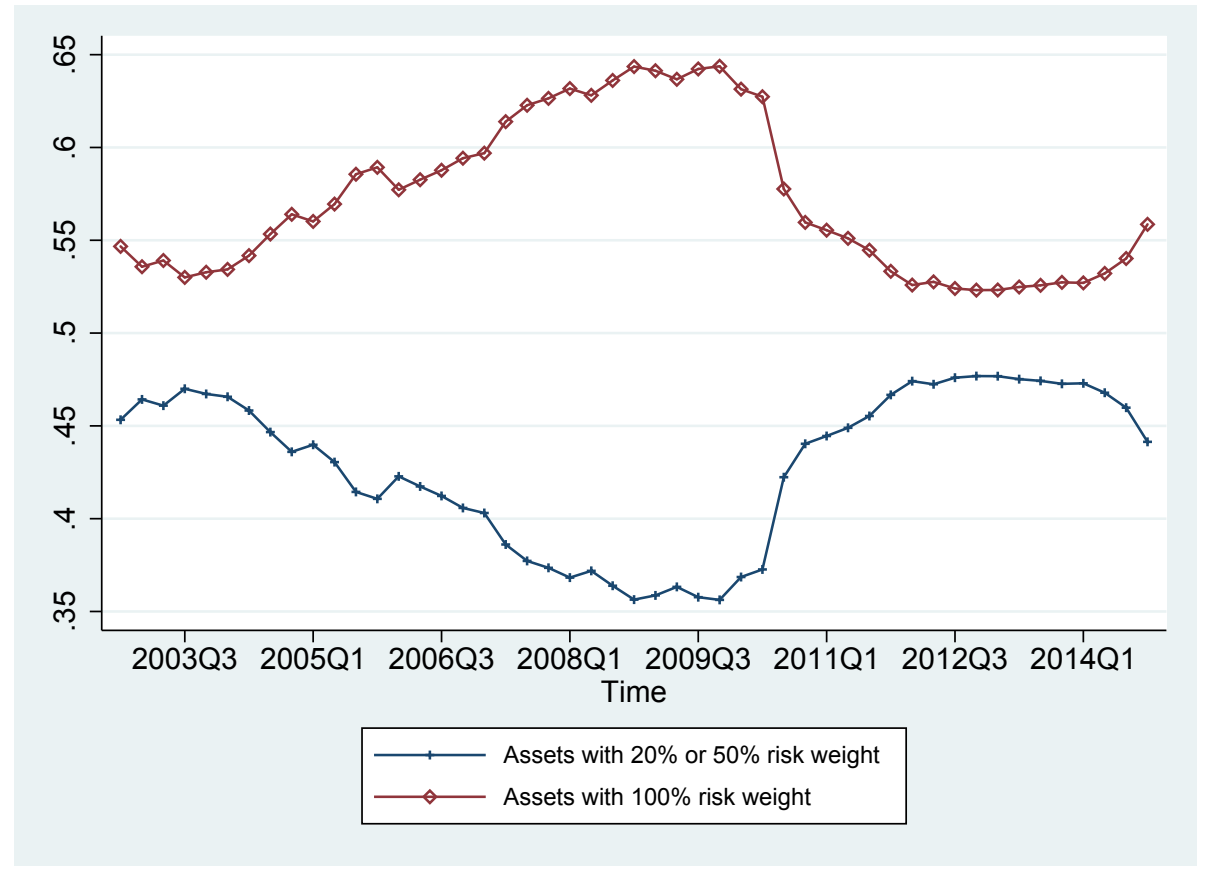

Figure 2: Banks' allocation among assets with nonzero risk weightings

This figure shows the proportions of high- and low-risk assets to total amounts allocated to risky assets, i.e. proportions of assets with $100 \%$ risk weight and proportions of assets with $20 \%$ and $50 \%$ risk weights, respectively, for all stand-alone banks and bank-holding companies in the U.S.

$3 \%$ while there are 97 banks that violate either the risk-weighted capital requirements in isolation or both the risk-weighted requirements and a leverage ratio of 3\%. These observations are in line with the claim in Choi et al. (2018) that the traditional leverage ratio requirement is rarely binding. For these reasons and the circumstance that the traditional leverage ratio has remained virtually unchanged over the whole sample period, we focus on the risk-based capital requirements of Basel I \& II. The risk-based capital-adequacy requirements pose additional costs for riskier assets, since banks have to reserve more capital for assets with a higher credit risk. How do banks react to such regulatory changes? Banks also have incentives to take more risk in order to gain higher earnings and compensate for the higher costs of their capital reserves. Thus, whether or not a tightening capital requirement would have the desired effect is an open question. 
To address the above-mentioned questions, we regard a bank as its assets ${ }^{7}$ manager and consider her portfolio allocation with a minimum regulatory capital requirement as a possible binding condition. Since our focus is on banks' risk-taking and asset allocation, we deliberately abstract from banks' interest setting behavior, screening and monitoring - in line with, e.g., Altman and Saunders (1998), Kealhofer and Bohn (2001), and Mencía (2012). We find that when a bank's capital is not constrained by regulation, its asset allocation decision depends on the risk measure of assets - namely, the cash-flow volatility around the expected loss due to default risk - and on the key measure of an asset's valuation, the Sharpe ratio (Sharpe, 1966), modified according to our settings. However, when the bank's capital is constrained by regulation, regulatory cost (risk weighting in risk-based capital regulation) steps in and weights the cash-flow volatility, and even replaces the volatility in the measure of the assets' valuation (reward-to-regulatory-cost ratio instead of Sharpe's reward-to-variability ratio). If the regulator imposes a new and more stringent regulation, banks might decrease or increase their risk exposure within their risky funds of assets depending on these reward-to-regulatory-cost ratios.

We test these implications using bank-level data on assets with different risk categories for all US banks. Since it takes years to formally implement each set of Basel rules, we focus on the shift from Basel I to Basel II. Moreover, since detailed information of assets in each risk category and consequently their credit risk is not available, we extract macro-level credit yields, default probabilities and default correlation based on corporates' credit ratings, used in the standardized approach under Basel II. The empirical examination largely verifies our predictions of how banks' choices between high-risk, high-earning assets and low-risk, low-earning assets react to the updated

\footnotetext{
${ }^{7}$ Banks hold different types of assets, such as loans and securities. Our model focuses on credit risk, which is the central risk facing commercial banks and also the main concern of capital regulation.
} 
information on assets' earnings and default probabilities, and we find that the implementation of a stricter regulation through the introduction of Basel II actually led them to increase the share of high-risk assets in the risky part of their portfolios.

Although there are theory models evaluating portfolio credit risk, only a few articles concern credit-portfolio optimization (see, e.g., Altman and Saunders, 1998; Kealhofer and Bohn, 2001; Mencía, 2012). Regarding the impact of capital regulation on banks' asset risk, the theoretical literature yields mixed predictions, with a few studies from the point of view of portfolio management (see, e.g., Koehn and Santomero, 1980; Kim and Santomero, 1988; Rochet, 1992; Furfine, 2001; Milne, 2002). An empirical study by Choi et al. (2018) shows that the supplementary leverage ratio, finalized in 2014, led affected banks (the very largest US banks) to shift their portfolios to riskier assets compared to similar banks not subject to the regulation. Our paper mainly contributes to the literature on banks' risk taking by analyzing banks' asset allocation explicitly with respect to credit risk and by disentangling the effects of risk-based capital regulation on banks' asset risk. To check the robustness of our results to the introduction of the supplementary leverage ratio, we exclude observations from 2014 (the last year in our sample), and the results remain the same. We realize that this is not a strong test of the robustness of our model, but it is the best we can do given the limitations of our data.

The remainder of the paper is organized as follows. Section 2 reviews the literature. In Section 3, we develop our hypotheses. In Section 4, we examine our hypotheses empirically using a panel data set and in the process, we include details on how we estimate conditional default probabilities, default correlation, and payoffs. Section 5 concludes. 


\section{Literature review}

Over the past two decades, we have seen important advances in the modeling of correlated defaults and the evaluation of portfolio credit risk, including Moody's KMV Portfolio Manager, JPMorgan's CreditMetrics, Credit Suisse's CreditRisk ${ }^{+}$, McKinsey's CreditPortfolioView, correlated default-intensity models, and copula-based modeling. ${ }^{8}$

Yet, there are only a few articles on credit-portfolio optimization. In addition to reviewing the literature, Altman and Saunders (1998) propose a new measure of the return-risk tradeoff, where they measure a portfolio's risk by its unexpected loss, determined by the standard deviation around the expected loss, which is estimated historically over time using bond rating equivalence: the $Z^{\prime \prime}$-score (Altman, 1993). Similarly, in a technical report from KMV (Kealhofer and Bohn, 2001), they measure unexpected loss by the standard deviation of loss only due to default in a default-only model, where there are two states; default and no default. Mencía (2012) models homogeneous loan classes, each comprising conditional independent loans whose conditional default probability is a probit function of a Gaussian state variable. He shows that, in his setting, mean-variance analysis is fully consistent with CRRA utility maximization. All three articles mentioned above adapt the mean-variance framework (Markowitz, 1952), to analyze the risk and returns on credit portfolios.

Regarding the impact of capital regulation on banks' asset risk, the theoretical literature yields mixed predictions, although there is general agreement about the immediate effects of stricter capital requirements on total bank lending and the longer-term impact on capital ratios. The immediate effects of stricter capital requirements are reduction in total lending, increases in market

\footnotetext{
${ }^{8}$ See detailed descriptions of the models by Gordy (2000), Crouhy et al. (2000), and Duffie and Singleton (2003), among others.
} 
loan rates and substitution away from lending to alternative assets. In the long-term, stricter capital requirements have been found to lead to an increase in capital ratios. However, there are largely divergent conclusions in the previous literature regarding how capital regulation influences individual banks' choices on the margin (see VanHoose, 2007, among others). As yet, there are just a few studies of banks' asset risk from the point of view of portfolio management. In light of the discussions surrounding the leverage ratio regulation, implemented in the US in 1981 (Volcker, 1987), Koehn and Santomero (1980) and Kim and Santomero (1988) consider a mean-variance portfolio-selection model, showing that a higher uniform regulatory capital ratio constrains the efficient asset investment frontier and might actually result in a higher asset risk and increase banks' insolvency risk, yielding the opposite of the intended effect. Nevertheless, Kim and Santomero (1988) model the optimal weights for the risk-based capital requirement, and predict that, with higher weights for riskier assets, banks would hold more liquid safe assets and fewer risky assets. Rochet (1992) argues that, if banks behave as portfolio managers - maximizing utility instead of the market value of their future profits as in Furlong and Keeley (1989), among others - capital regulation can be effective, but only if the risk weights are proportional to the systematic risks of the assets (their betas). Furfine (2001), developing a dynamic value-maximizing model and calibrating it to U.S. data, finds that Basel I was involved in the credit crunch experienced in the 1990s and predicts that, under Basel II, banks would increase loans relative to securities and safer loans relative to risky ones. Milne (2002) interprets capital regulation as a system of sanctions for ex post violation instead of ex ante enforcement, and his value-maximizing model suggests that there is relatively less need to match risk weightings accurately to portfolio risk.

Based on the framework developed by Koehn and Santomero (1980) and Kim and Santomero (1988) we set up a portfolio-selection model that allows us to study the effects of risk-based capital 
regulation explicitly. However, in our model, the bank manager maximizes the utility of one-period net value of assets, instead of the utility of equity returns, as in their models. The obvious advantage of using the utility of assets' net value is its focus on the bank's asset risk, which we believe is closer to established practice.

The most marked difference from the aforementioned banking literature is that this paper focuses on credit risk, where there are only two conditional states: default and no default. Thus, we can adapt similar approaches from the credit-portfolio-optimization literature (Altman and Saunders, 1998; Kealhofer and Bohn, 2001; Mencía, 2012). Moreover, we study whether banks restructure their portfolios from low-risk, low-earning assets to high-risk, high-earning assets to compensate for additional costs imposed by capital requirements.

In an independently developed paper, Choi et al. (2018) show that the supplementary leverage ratio, completed in 2014, led affected banks (the very largest US banks) to reallocate their portfolios towards riskier assets as compared to similar banks not subject to the regulation. As compared to their study, ours combines theory and empirics to analyze the effect of stricter risk-based capital regulation on banks' risk-taking.

\section{Hypotheses development}

In order to fix ideas, we develop a single-period, three-asset (risk free, low risk, high risk) model of banks' portfolio allocation. All of the details of this model are in the Internet Appendix and the main results are in Appendix A. In this section, we describe this model and its testable implications.

We model a bank as its asset manager, who makes one-period decisions on allocating resources (deposits and capital) for the assets with different levels of credit risk; its capital might be constrained 
by risk-based capital regulation. The model predicts how the bank manager restructures the portfolio of different assets when their conditional default probabilities, default correlation, or payoffs change, or when the regulator tightens risk-based capital requirements. Since we focus on banks' risk-taking, we deliberately abstract from banks' interest rate setting behavior, screening and monitoring.

The bank aims to maximize a single-period expected quadratic utility of its assets' random cash profit, and the expected utility is an increasing function of the expected cash flow and a decreasing function of the cash-flow variance. ${ }^{9}$ The bank chooses among three types of asset: a high-risk, high-earning asset; a low-risk, low-earning asset; and a risk-free asset. ${ }^{10}$ For simplicity, only the relative sizes of assets are assumed to be under the control of bank management. ${ }^{11}$ In addition, the regulator decides that the bank has to hold capital as minimum $k$ times the total risk-weighted assets, where risky assets are assigned higher weights. It is also assumed that the holding period perfectly matches the maturity of the assets. All assets are in perfectly elastic supply, i.e., the bank is a price taker. Liabilities, capital and deposits are exogenous, so this is a pure asset management problem (no liability management) to which standard quadratic utility (CAPM) results apply.

Absent of capital requirements, the portfolio allocation depends on a modified Sharpe ratio, depending on default risk and cash flow volatility. With binding capital requirements, however, there is a bias either away from or towards high-risk assets. Which of these two possibilities arises

\footnotetext{
${ }^{9}$ Bawa and Lindenberg (1977) show that, as long as the expected utility can be written as an increasing function of the expected return and a decreasing function of the variance of the portfolio only, without any assumption of probability distributions of assets' returns, the optimal portfolio lies on the efficient frontier in the mean-variance framework of Markowitz (1952). Also, when there is a risk-free asset, the two-fund theorem is valid. Here, by applying a quadratic utility function, we could sidestep most of the problems associated with solving a general utility-based portfolio choice and obtain an analytical solution.

${ }^{10}$ The choice of three types of assets is also consistent with the empirical examination in Section 4. In addition, the model with four types of assets, which corresponds to the four risk categories of assets in the Basel Accords, is qualitatively identical.

${ }^{11}$ This simplification serves the purpose of this study. While we could enrich the model with additional features, such as variations in the bank's liabilities and capital, how the bank allocates among assets with different credit risks in a ceteris paribus environment is not altered.
} 
depends on the relative ratio of returns and regulatory capital costs for the two types of asset.

If there are no capital constraints, the usual two-fund separation theorem applies (Tobin, 1958) so the portfolio of risky assets maximizes the Sharpe ratio. As capital requirements are introduced and become binding, we find that there is a shift in asset composition, depending on the parameter

$$
\vartheta \equiv \frac{\vartheta_{h}}{\vartheta_{l}}=\frac{\left(\mu_{h}-r_{f}\right) W_{l}}{\left(\mu_{l}-r_{f}\right) W_{h}}
$$

where $\mu_{h}$ and $\mu_{l}$ are the expected returns of the high-risk and low-risk assets, respectively, and $W_{h}$ and $W_{l}$ are the corresponding risk weights, whereas $r_{f}$ is the risk-free rate. Further, $\vartheta_{h}$ and $\vartheta_{l}$ are the reward-to-regulatory cost ratios, defined as $\vartheta_{h}=\left(\mu_{h}-r_{f}\right) / W_{h}$ and $\vartheta_{l}=\left(\mu_{l}-r_{f}\right) / W_{l}$, respectively (Proposition 3 in the appendix). The $\vartheta$ parameter captures the relative importance of capital requirements and the excess return for the two risky assets.

A binding capital requirement has two effects. First, it limits the ability to accept risk, resulting in a portfolio shift towards the risk-free fund. Second, there might be a reallocation of the risky fund, either towards the high risk asset or the low risk asset. This latter reallocation effect might offset the risk reduction resulting from the shift towards the risk-free fund. The adjustment of the risky fund depends crucially on the parameter $\vartheta$ (see Proposition $3 \mathrm{a}$ in the appendix).

If $\vartheta=1$, then adjustment of the risky fund would lead to a detoriation in risk-return tradeoff (the portfolio Sharpe ratio) without any compensating loosening of the capital constraint. Thus, in this case, there is no adjustment within the risky fund, and the two-fund separation theorem continues to apply.

If $\vartheta>1$, then the bank can loosen a binding capital constraint (at the cost of worsening the Sharpe ratio) through shifting the risky fund towards the more capital-efficient high-risk asset. Conversely, if $\vartheta<1$, then the bank can achieve a loosening of the binding capital constraint by the 
opposite portfolio shift, into the more capital-efficient low-risk asset. In both of these cases, the usual two-fund separation result no longer holds: the investment in the risk-free asset can be less than for the case when $\vartheta=1$.

In addition, Proposition 2 shows the effects of monetary policy on banks' risk-taking: according to the proposition, an environment with a lower risk-free rate results in higher risk-taking among banks.

Given this theoretical background, we aim at testing whether the variables that are identified as important for portfolio choice in Proposition 1 in the appendix are significant and carry the predicted signs. Also, given the ambiguous answers provided by our reasoning as well as the previous literature, another objective is to investigate whether banks' risk taking increases or decreases in response to stricter regulation.

\section{Empirical examination}

This section tests the model on U.S. stand-alone commercial banks and bank-holding companies. The sample is comprised of 1721 banks with quarterly consolidated bank-level data from the first quarter of 2002 to the fourth quarter of 2014. Due to concerns regarding domestic and international competitiveness, the implementation of capital regulation in the U.S. closely follows the Basel Accords. ${ }^{12}$

Since detailed information on each bank's assets with certain risk weighting $-0 \%, 20 \%, 50 \%$, or $100 \%$ - is not available due to business confidentiality, we use macro-level data on the corporations

\footnotetext{
${ }^{12}$ General risk-based capital rules based on Basel I have been implemented since 1989; the standardized approach for general banking organizations and the advanced internal ratings-based approach for core banks, based on Basel II, have been implemented since 2008. Core banks are those with consolidated total assets of $\$ 250$ billion or more or with a consolidated total on-balance-sheet foreign exposure of $\$ 10$ billion or more (Treasury, the Federal Reserve System, and Federal Deposit Insurance Corporation, 2007, 2008).
} 
with external ratings corresponding to assets' risk weighting according to Basel II to assess assets within each risk category. Thus, the credit risk and payoff of the bonds issued by those corporations are used to proxy the credit risk and payoffs of each bank's assets within one risk category. ${ }^{13}$ In terms of statistical tests, we first investigate whether banks absorb the market-wide macro information on credit risk in their decision making on asset allocations as suggested by the model. Second, we test the impact of a tightening capital regulation on banks' asset allocations.

\subsection{Data}

All financial-statement variables are drawn from quarterly filings of commercial banks' or bank holding companies' reports to the Federal Reserve for regulatory purpose. All data are collected from Standard \& Poor's Capital IQ database, unless otherwise stated.

For macro-level estimates of assets' credit risk and payoff, we use Standard \& Poor's long-term corporate ratings, the data on the corporations' actual defaults, and yields of bonds issued, extracted from the Capital IQ database. The sample is comprised of all issuers of senior unsecured corporate debentures in the market. Thereafter, we estimate the default probability of each group of corporations with certain bond ratings, and the default correlation with another group of corporations holding other bond ratings. To value the macro-level payoff of assets, we use average yield ${ }^{14}$ of those bonds issued by the corporations holding certain ratings.

We use corporate bond data to proxy asset returns and risk. Since corporate bonds are just senior to stocks and tied to the issuers' credit risk, the default risks and yields of corporate bonds

\footnotetext{
${ }^{13}$ Note that we do not focus on banks' bond allocations; we merely use credit risk and payoffs of corporate bonds within each risk category to proxy for the credit risk and payoffs of all assets (mainly loans) in that risk category.

${ }^{14}$ Since the yield on a bond already accounts for its associated risk, using yield would underestimate the payoff of a type of asset. Nevertheless, the average yield in the market provides a macro level (actually a macro low bound) of the average payoff of the type of asset, which is comparable across time.
} 
can be viewed as measures of the market's perception of corporations' credit risks and market compensations for these risks. Since banks lend to corporations to a large extent, the corporations' credit risks and the market compensations for these risks should be indicative of that of banks' assets. Our approach is in line with the practice of using bond-rating equivalents to evaluate corporations' credit risk (Altman et al., 2010).

\subsection{Asset categories}

Under the standardized approach in Basel Accord II, assets are classified into different risk categories according to their external ratings when the ratings are applicable. Based on Basel Accord II and the requirements for Call Reports, the ratings corresponding to assets with $20 \%, 50 \%$, and $100 \%$ risk are $\mathrm{AAA}$ to $\mathrm{AA}, \mathrm{A}$, and $\mathrm{BBB}$ to $\mathrm{BB},{ }^{15}$ respectively.

Yet, there are so few observations of defaults for corporations holding ratings AAA to AA, or A, that the result is a zero default rate in much of the sample period. Therefore, we combine assets with $20 \%$ and $50 \%$ risk, and assign them an average risk level of $35 \%$. Consequently, there are three types of asset in the sample: risk-free assets, low-risk, low-earning assets, and high-risk, high-earning assets, with $0 \%, 35 \%$, and 100\% risk, respectively, consistent with the model in Section 3 . Hence, the credit qualities of low- and high-risk assets are proxied by the market-wide bond issuers holding ratings $\mathrm{AAA}$ to $\mathrm{A}$ and $\mathrm{BBB}$ to $\mathrm{BB}$, respectively.

\footnotetext{
${ }^{15}$ According to the instructions for Call Reports, only the ratings above B are eligible for the ratings-based approach. Although, in accordance with the Dodd-Frank Wall Street Reform and Consumer Protection Act, the U.S. rules do not reference external credit ratings from 2010, in practice U.S. banks often use external ratings: see Regulatory Consistency Assessment Programme (RCAP), Assessment of Basel III regulations - United States of America, available at www.bis.org/bcbs/publ/d301.pdf.
} 


\subsection{Estimating default probability, default correlation, and payoff}

We estimate the probabilities of default by empirical average cumulative default rates for a historical time period, as is commonly done by the major rating agencies. These historical default rates, based on issuer, give equal weights to all issuers in the calculation, regardless of differences in the nominal size of the bonds issued by each issuer. ${ }^{16}$ This approach is also cohort based, i.e., we track the default rates of firms with a certain rating on a given calendar date, and this pool of issuers constitutes a cohort. We adopt the method of calculating average cumulative default rates with adjustment for rating withdrawals used by Moody's, as demonstrated by Cantor and Hamilton (2007). We then modify their methodology to estimate the default correlations. The methods are described in Appendix B.

In a nutshell, we group corporations by ratings (AAA to A for group 1 and $\mathrm{BBB}$ to $\mathrm{BB}$ for group 2) in the beginning of a period. Then, for each group, we track the number of defaults in the following periods. For example, with a four-period window, for each group, this tracking gives us four marginal default rates (named $d_{11}, d_{12}, d_{13}$ and $d_{14}$ ) after grouping in period 1 . We can calculate a cumulative default rate based on these marginal default rates conditional on survival (see equation (B.1)). We also do the same grouping in period 2 (resulting in three marginal default rates, named $d_{21}, d_{22}$ and $d_{23}$ ), period 3 (resulting in two marginal default rates, named $d_{31}$ and $d_{32}$ ), and period 4 (resulting in one marginal default rate, named $d_{41}$ ). Then, we calculate an average marginal default rate for each period after grouping. For example, the average marginal default rate for the first period after grouping is an average of $d_{11}, d_{21}, d_{31}$ and $d_{41}$, the one for the second period after grouping is an average of $d_{12}, d_{22}$ and $d_{32}$, and so on. Finally, we take an average over

\footnotetext{
${ }^{16} \mathrm{We}$ use average default information on issuers instead of issues to obtain the low bound of the macro level of default, since the ratings of issues are generally not higher than that of their issuer.
} 
all the average marginal default rates for the first, second, third and fourth period after grouping, and this gives us the average cumulative default rates that are used in our statistical tests.

Simultaneously, we calculate a default correlation indicating whether the marginal default rates of the two groups change in the same direction (i.e., go up or down together) or in opposite directions (i.e., one goes up while the other goes down). First, we calculate average pairwise marginal default rates of both groups for the first period after grouping based on $d_{11}, d_{21}, d_{31}$ and $d_{41}$ from each group. The average pairwise marginal default rates and the marginal default rates of each group give us a marginal default correlation for the first period after grouping. Then, in the same way, we calculate the marginal default correlation for the second period after grouping based on $d_{12}, d_{22}$ and $d_{32}$, and for the third period after grouping based on $d_{13}$ and $d_{23}$. Notice that there is no default correlation for the fourth period because there is only one period and we cannot track the change of defaults in the groups. Finally, the average over the three marginal default correlations gives an estimate of the default correlation over four periods (see equation (B.2)).

At the end of the four periods, we can also observe the four-period yields of bonds issued by the corporations in each group. The average yield in each group represents the return that is associated with the default risk of the corporations in that group.

Since there are relatively more default observations on a quarterly basis than on a monthly basis, especially for investment-grade corporations, we employ quarterly cohort spacing, which also produces more accurate estimates of default correlations. For the same reason, we also choose a longer investment horizon of four years. ${ }^{17} \mathrm{We}$ assume that, when banks' managers make portfolio

\footnotetext{
${ }^{17}$ We perform robustness checks on two-year and three-year default rates and correlations: the results are qualitatively similar. The maximum possible length of the estimation window is four years because the data on actual defaults date back to 1998.
} 
asset choices, they hold expectations on default probabilities and default correlations based on the historical information during the previous four years.

To estimate the credit risk and payoffs of the assets with a certain risk type and the creditworthiness of issuers, we only employ senior unsecured straight bonds: fixed-rate, U.S.-dollar bonds without any asset-backing or credit-enhancement - e.g., callability, puttability, sinking, or convertibility. We then estimate the payoff of each asset type at a date by an average of four-year-to-maturity yields ${ }^{18}$ at that date on all available straight bonds whose issuers hold certain ratings.

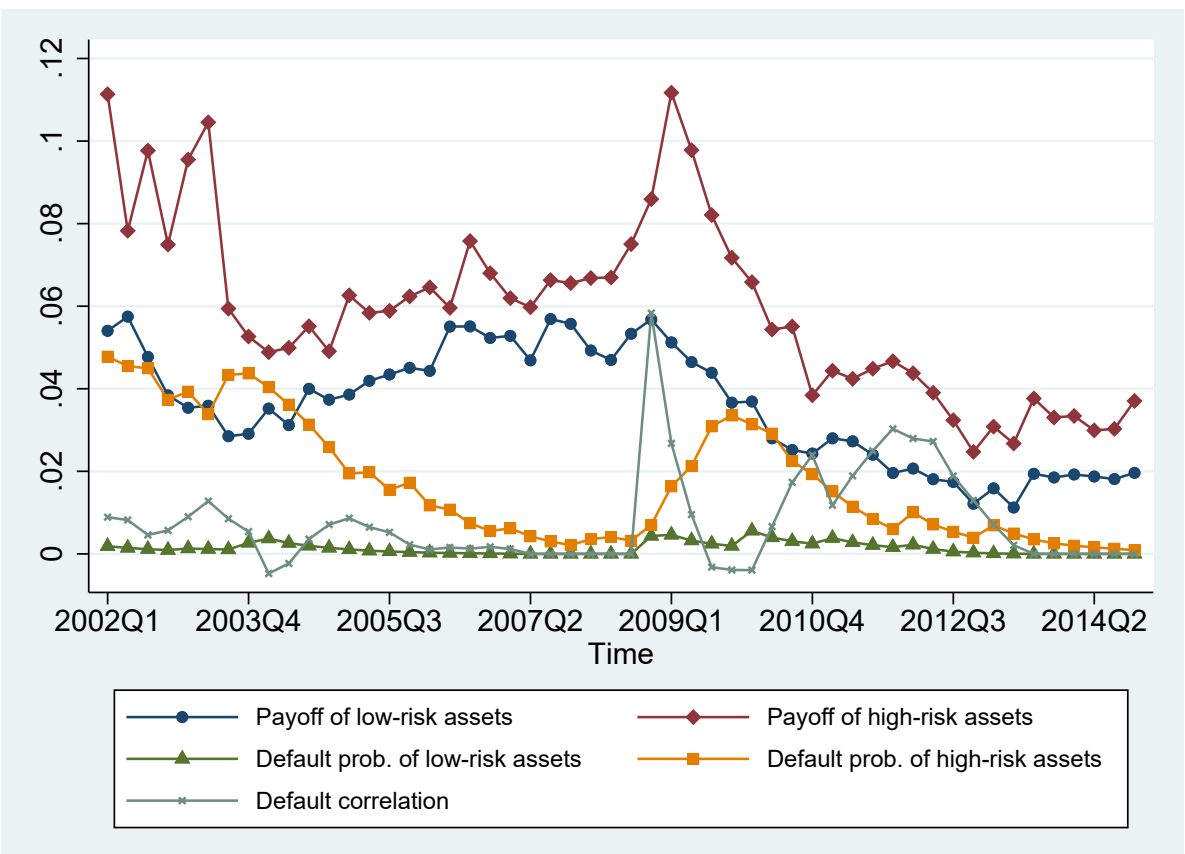

Figure 3: Macro-level estimates of credit risk and payoffs

Payoff, Default prob., and Default correlation are estimated based on average macro credit information on the risky assets. The estimated payoffs, default probabilities, and default correlation (in percentage) are calculated at the beginning of each quarter.

Figure 3 shows our estimates of macro-level information of credit risk, namely yields, default probabilities and default correlations. As explained above, these estimates are based on average cumulative default rates over a four-year period and average four-year-to-maturity yields and

\footnotetext{
${ }^{18}$ The yield that represents one issuer is an average of yields on all available straight bonds issued by that corporation.
} 
are used to proxy payoffs and default probabilities of high- and low-risk assets and their default correlation. The figure shows evidence of cyclicality in credit risk. The trends in payoffs and default probabilities of high-risk assets mimic those in allocations to high- and low-risk assets in Figure 2. One should, however, keep in mind that average cumulative default rates over a four-year period can be quite different from simple annual default rates. Naturally, there can be a lag before one starts to see the effects of sudden changes. Moreover, our payoffs are calculated based on four-year yields and are thus forward-looking. When possible, we check our estimates against Standard \& Poor's annual corporate default studies and the FRED database, and we find that similar patterns as those in Figure 3 emerge also in these data sets. Since we use similar methods and get similar results as major rating agencies (Standard \& Poor's, Moody's, etc) and banks often use their figures, we believe that our estimates are similar to what banks would actually use as inputs. However, since figures are not available for our rating groups, we construct our own estimates. By doing so, we also facilitate replication and increase transparency.

\subsection{CAMELS variables}

We use CAMELS variables as controls in our regressions. CAMELS is a ratings system used by, e.g., U.S. banking supervisory authorities to assess a bank's overall condition (see Duchin and Sosyura, 2012; Li, 2013, among others). The letters in the acronym stand for Capital adequacy, Asset quality, Management capability, Earnings, Liquidity and Sensitivity to market risk, respectively, and we include proxies to quantify these concepts in our regressions.

Specifically, to proxy Capital adequacy, we use the logarithm of the ratio of total equity to total assets and we call this variable "Equity ratio." We measure Asset quality by using nonperforming assets over total assets and we term this variable "Nonperforming assets." To proxy for Management 
capability, we calculate total expenses to total income which, in a sense, is a measure of operating inefficiency. ${ }^{19}$ In order to capture Earnings, we simply use the return on assets (ROA). Further, Liquidity is measured as the ratio of liquid assets to total assets, where "liquid assets" is automatically calculated by Capital IQ, and we call the aforementioned ratio "Liquid assets" in the regressions. Finally, in line with previous studies, we use the ratio of the absolute value of noninterest income to the sums of the absolute values of noninterest and interest income to capture Sensitivity to market risk, and we term this variable "Noninterest income."

\subsection{Results}

Table 1 summarizes statistics of the data on the variables used in the empirical tests. Proportion of high-risk assets and Proportion of low-risk assets are the banks' actual shares of high-risk (100\% risk) and low-risk (20\% and 50\% risk) assets among the risky (20\%, 50\%, and 100\% risk) assets, respectively. Thus, they sum to one for each bank. Consistent with Figure 2, on average, banks allocate resources more to high-risk assets. The Payoff and Default probability of each type of risky asset and their Default correlation are the average macro credit information from our estimation. Consistent with the assumptions in the model, high-risk assets have higher probability of default and payoff compared to low-risk assets. These variables are used to test whether banks do absorb macro credit information in the expected direction.

Basel II is a dummy variable for the quarters since the agreed-upon text for Basel II was released; unless stated otherwise, we use the third quarter of 2004 as the starting date of Basel II. As a

\footnotetext{
${ }^{19} \mathrm{An}$ exception in which it would not be an appropriate measure would be if the aforementioned ratio is negative-representing high efficiency-due to a negative income and thus we treat these cases as missing values. However, if this ratio is negative due to negative expenses, it still aligns well with the other values, and thus we include such numbers in our empirical analysis.
} 
Table 1: Summary statistics of the data

Proportion of high-risk assets and Proportion of low-risk assets are the proportions of banks' allocations within risky assets. Therefore, for each bank, they sum to one. Payoff, Default prob., and Default correlation are based on the average macro credit information on the risky assets from our estimation. Other bank-level variables are Size (total assets in billions of dollars), Equity ratio (the ratio of total equity to total assets), Nonperforming assets (the ratio of nonperforming assets to total assets), Cost-to-income ratio (the ratio of total expenses to total income), Noninterest income (the ratio of the absolute value of noninterest income to the sums of the absolute values of noninterest and interest income), Return on assets, and Liquid assets (the ratio of liquid assets to total assets). The estimated payoffs, default probabilities, and default correlation (in percentage) are valued at the beginning of each quarter.

\begin{tabular}{lccccc}
\hline VARIABLES & Observations & Mean & Std. Dev. & Min. & Max. \\
\hline Proportion of high-risk assets & 59,441 & 0.598 & 0.163 & 0 & 1 \\
Proportion of low-risk assets & 59,441 & 0.402 & 0.163 & 0 & 1 \\
Payoff of low-risk assets & 59,441 & 0.036 & 0.014 & 0.011 & 0.058 \\
Payoff of high-risk assets & 59,441 & 0.060 & 0.022 & 0.025 & 0.112 \\
Default prob. of low-risk assets & 59,441 & 0.001 & 0.001 & 0 & 0.006 \\
Default prob. of high-risk assets & 59,441 & 0.019 & 0.015 & 0.001 & 0.048 \\
Default correlation & 59,441 & 0.008 & 0.011 & -0.005 & 0.058 \\
Size & 59,441 & 6.532 & 82.17 & 0.0004 & 2,573 \\
Ln(Size) & 59,441 & -0.686 & 1.491 & -7.927 & 7.853 \\
Equity ratio & 59,441 & 0.107 & 0.065 & 0.0002 & 1.183 \\
Nonperforming assets & 55,479 & 0.020 & 0.031 & $3.98 \mathrm{E}-07$ & 0.476 \\
Cost-to-income ratio & 59,049 & 0.804 & 0.709 & -14.93 & 84.67 \\
Noninterest income & 59,007 & 0.155 & 0.123 & $3.20 \mathrm{E}-05$ & 1 \\
Return on assets & 19,221 & 0.007 & 0.017 & -0.482 & 0.273 \\
Liquid assets & 59,436 & 0.218 & 0.127 & 0.0002 & 1 \\
\hline
\end{tabular}

robustness check, we re-run all our estimations with the date of the first implementation, i.e., the second quarter of 2008 as the starting date of Basel II and all the results remain qualitatively the same. One important reason for using the third quarter of 2004 rather than the second quarter of 2008 as the starting date of Basel II in the main specification is the possible confounding effects of the financial crisis if we would have used the latter alternative. We use Basel II as a proxy for a tightened capital requirement. This approximation is applicable since an asset's risk is valued by the type of its obligors under Basel I instead of by the actual risk of the obligors. For example, assets involving banks in OECD countries are classified as $20 \%$ risk category under Basel I; however, among these, those whose obligors have high credit risk will fall to $50 \%$ or $100 \%$ risk category under Basel II. The remaining variables are bank-level controls. 


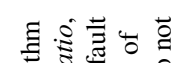

要

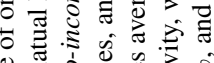

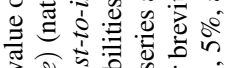

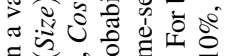

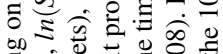

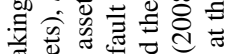

o

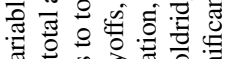

$>0$ 品

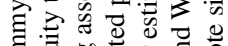

Ð छ

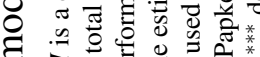

$\checkmark$ 넝

艺

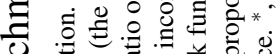

氜

ป

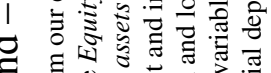

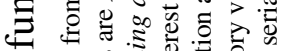

友

象

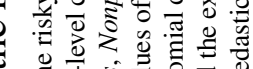

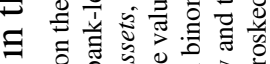

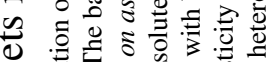

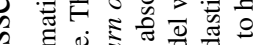

व

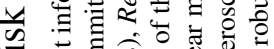

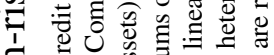

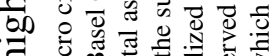

코 흔

낭

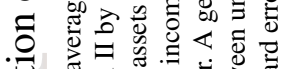

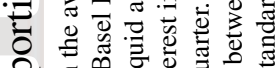

on

竞

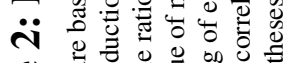

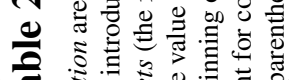

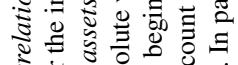

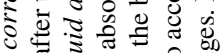
$\leftarrow$ ज. ฟ ๑ักิ 亭

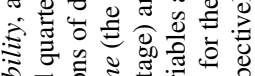

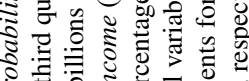

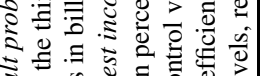

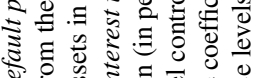

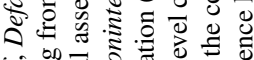

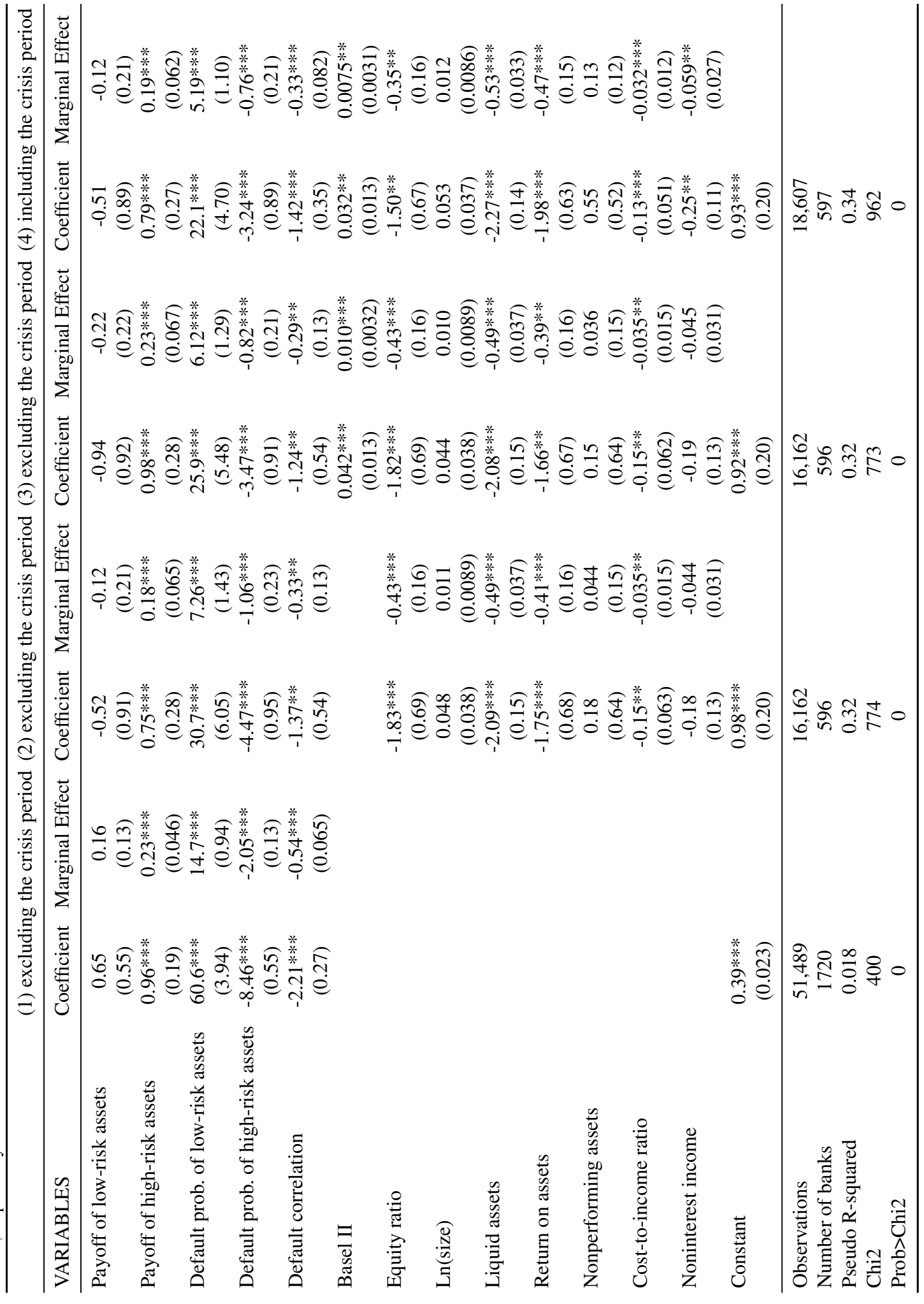

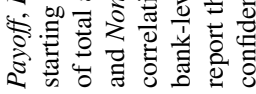


Table 2 presents our baseline results. We find that, except for the payoff of low-risk assets, all key variables are significant and all have the signs that we expect from Proposition 1 in the appendix. Since the correlation is about 0.75 , however, it is hard to distinguish between the effects of the returns on high-risk and low-risk assets, which might explain the insignificance of the coefficient related to the return on the low-risk assets. The positive effect of the Basel II dummy suggests that the stricter regulation under Basel II actually led to a higher proportion of high-risk assets within their risky portfolios, which seems counter-intuitive at first sight, but this is exactly what might happen according to Proposition 3: we show that it could both lead to lower and, more interestingly, higher proportions of high-risk assets, and it is in fact this latter effect that is present in our data.

As a further test of the effect of risk-taking of a stricter capital regulation, we estimate our model from the second specification in Table 2 for unconstrained banks in the Basel I period and use the predictions from that model in the Basel II period to investigate whether banks that become constrained in the Basel II period take higher or lower risks (according to Proposition 3, it could go either way). ${ }^{20}$ More specifically, we identify banks that become constrained under Basel II by using the following approach:

(i) We use observations on unconstrained banks in the Basel I period to estimate our model in specification 2 in Table 2.

(ii) We use the parameter estimates from (i) to predict how banks would behave in the Basel II period given Basel I-type reactions. If a bank should have been unconstrained in the Basel II period according to our prediction, but is actually constrained, we consider it as having become constrained as we move from Basel I to Basel II.

\footnotetext{
${ }^{20}$ We say that banks are unconstrained if their risk-based capital ratio is equal to or higher than $8 \%$, which is the requirement under Basel I and II for banks using the standardized approach.
} 
Table 3: Actual allocation vs. prediction during Basel II

We estimate the model in specification (2) in Table 2 for banks that are unconstrained during the Basel I period, and use it to predict the proportion of high-risk assets after the implementation of Basel II. This table displays the banks that become constrained during Basel II.

\begin{tabular}{lccccc}
\hline Variable & Obs. & Mean & Std. Dev. & Min. & Max. \\
\hline Proportion of high-risk assets & 5 & 0.810 & 0.069 & 0.745 & 0.886 \\
Predicted proportion of high-risk assets & 5 & 0.727 & 0.065 & 0.654 & 0.800 \\
Difference of actual allocation with the prediction & 5 & 0.083 & 0.027 & 0.040 & 0.113 \\
Risk-based capital ratio & 5 & 7.836 & 0.111 & 7.67 & 7.95 \\
\hline
\end{tabular}

Using this method, we single out five banks that become constrained in the Basel II period. For this (admittedly limited) sample, we find that those five banks actually all hold higher shares of high-risk assets in their risky portfolios as compared to what they would be expected to do under Basel I and the difference between the actual and the expected allocation to high-risk assets is significantly positive (see Table 3). That is, the stricter regulation incurred by Basel II actually led all considered banks to increase the share of high-risk assets, something which might occur according to Proposition 3 in Appendix A. In the baseline setting, we include the financial crisis period, but we get a similar result if we exclude it - the only difference being that the number of banks that become constrained is reduced to three. The result is also robust to using the second quarter of 2008 as the starting date of Basel II. Further, among all the banks that are unconstrained (by the risk-based capital ratio) in the Basel I period and that we use for the predictions in Table 3, there is only one bank that has a Tier 1 leverage ratio below $4 \%$ (but it is still above $3 \%$, which is the lowest permitted leverage ratio according to US regulation).

\section{Conclusion}

This paper explicitly investigates the credit risk of banks' assets and addresses banks' portfolio allocations under risk-based capital regulation. Drawing on the credit portfolio optimization 
literature, we disentangle the effects of risk-based capital regulation on the credit risk of banks' assets.

When risk-based capital regulation is binding, the risk weightings assigned by the regulator affect the original measures of risk and valuation of assets: namely, volatility around expected loss due to default risk and Sharpe ratio, respectively. This raises concerns that, if the risk weightings are not consistent with the assets' true risk measures, there could be opportunities for regulatory arbitrage so that banks invest more in assets with a high level of true risk but a low regulatory risk weighting. If the regulator imposes a new, and more stringent, regulation, the bank whose capital is already constrained will skew the risky portfolio to high-risk, high-earning assets, provided that the reward-to-regulatory-cost ratio of high-risk assets is higher than that of low-risk assets. If the reward-to-regulatory cost ratio of high-risk assets is instead lower than that of low-risk assets, we get the opposite result.

The empirical tests support our hypotheses. Due to business confidentiality, detailed data on each asset of each bank are not available. Yet, the average macro information on payoffs and credit risk of assets in each risk category that we estimate is very helpful in explaining banks' actual asset choices. More specifically, the tests support the predictions of a flight towards higher returns and an avoidance of default risk. We also find that banks reacted to the implementation of the stricter Basel II rules by holding a higher fraction of high-risk assets within their risky portfolios.

Our study contributes to the literature and to ongoing debates on banks' risk taking and capital regulation from the perspective of credit risk, which, it is hoped, paves a way for future research on banks' asset risk. For example, our empirical analysis could be enriched by using detailed data on assets at the individual-bank level. 


\section{Author Biographies}

Frederik Lundtofte is an Associate Professor at the Department of Economics and a member of the Knut Wicksell Centre for Financial Studies at Lund University, Sweden. He received his PhD in Economics from Lund University in 2005, after which he worked as a post-doctoral research fellow at the University of St. Gallen, before returning to Lund in 2007. He has published several research articles on portfolio choice, asset pricing and banking in well-established academic journals, such as the European Economic Review, Economica and the Journal of Banking and Finance.

Caren Yinxia Nielsen is a post-doctoral research fellow at the Center for Corporate Governance at Copenhagen Business School in Denmark and a guest researcher affiliated with the Knut Wicksell Centre for Financial Studies at Lund in Sweden. She obtained a PhD in Financial Economics from Lund University in 2015. She is doing research on banking, bank regulation, portfolio choice and asset pricing, and working on multidisciplinary projects with management and law experts. 


\section{Appendix A: A simple model of banks' asset allocation}

Here, we present the main results from a simple, one-period model of banks' asset allocation, where we assume that the bank (embodying the behavior of its manager) maximizes the expected utility of its future cash profit, using a quadratic elementary utility function. The details (model description, proofs, etc) are in the Internet Appendix.

\section{A.1. Optimal portfolio allocation when the capital requirement is not binding}

When the capital requirement is not binding, we can establish the following two propositions regarding the risky and the riskfree fund, respectively.

Proposition 1. Within the risky fund, the bank invests proportionally more (less) in high-risk assets, ceteris paribus, if

(a) its payoff, $C_{\mathrm{h}}$, increases (decreases); or

(b) its probability of default, $p_{\mathrm{h}}$, decreases (increases); or

(c) the payoff of the low-risk asset, $C_{1}$, decreases (increases); or

(d) the default probability of the low-risk asset, $p_{1}$, increases (decreases); or

(e) i. the default correlation, $\rho$, increases (decreases) provided that $S R_{\mathrm{h}}>S R_{1}$; or

ii. the default correlation, $\rho$, decreases (increases) provided that $S R_{\mathrm{h}}<S R_{1}$.

Proposition 2. The bank invests more (less) in the risk-free fund, ceteris paribus, if

(a) the risk-free rate $r_{\mathrm{f}}$ increases (decreases); or

(b) the payoff of the high-risk asset, $C_{\mathrm{h}}$, increases (decreases), given that $\rho \sqrt{V_{\mathrm{h}}} \geq \sqrt{V_{\mathrm{l}}}$; or

(c) the default probability of the high-risk asset, $p_{\mathrm{h}}$, decreases (increases), given that $\frac{\rho \sqrt{V_{\mathrm{h}}}}{\sqrt{V_{1}}} \geq$ $\frac{2 X_{\mathrm{h}}}{X_{\mathrm{h}}+X_{\mathrm{l}}}>1 ;$ or 
(d) the payoff of the low-risk asset, $C_{1}$, decreases (increases), given that $\frac{\rho \sqrt{V_{\mathrm{h}}}}{\sqrt{V_{1}}} \geq \frac{X_{\mathrm{h}}+1+r_{\mathrm{f}}}{X_{1}+1+r_{\mathrm{f}}}$, $\rho^{2} X_{\mathrm{h}} \geq X_{1}, \rho\left(1+r_{\mathrm{f}}\right)>X_{1}$ and $\frac{X_{\mathrm{h}}^{2}}{X_{1}^{2}} \geq \frac{V_{\mathrm{h}}-\rho \sqrt{V_{\mathrm{h}} V_{1}}}{V_{1}-\rho^{2} V_{1}} ;$ or

(e) the default probability of the low-risk asset, $p_{1}$, increases (decreases), given that $\rho \sqrt{V_{\mathrm{h}}} \geq \sqrt{V_{1}}$ and $S R_{1}^{2} \leq 1-\rho^{2} ;$ or

(f) the default correlation, $\rho$, increases (decreases), assuming $\rho \sqrt{V_{\mathrm{h}}} \leq \sqrt{V_{1}}$ and $S R_{\mathrm{h}} \geq S R_{\mathrm{l}}$.

$S R$ stands for Sharpe ratio (Sharpe, 1966), modified according to the settings in our model.

\section{A.2. Impact of risk-based capital regulation}

The following proposition shows how the bank reshuffles the portfolio due to new and more stringent capital regulation, such as an increase in the risk-based capital requirement, $k$.

Proposition 3. When the bank's capital is constrained by regulation and the regulator imposes a new and more stringent regulation with a higher capital requirement $k$,

(a) within the risky fund, the bank invests proportionally more (less) in high-risk assets, ceteris paribus, if $\vartheta_{\mathrm{h}}>\vartheta_{\mathrm{l}}\left(\vartheta_{\mathrm{h}}<\vartheta_{\mathrm{l}}\right)$, and

(b) the bank invests more in the risk-free fund, ceteris paribus, given that $\vartheta_{\mathrm{h}} \geq \vartheta_{1}$ and $\rho \varphi_{\mathrm{l}} \geq \varphi_{\mathrm{h}}$.

Here, $\vartheta_{h} \equiv\left(\mu_{h}-r_{f}\right) / W_{h}, \vartheta_{l} \equiv\left(\mu_{l}-r_{f}\right) / W_{l}, \varphi_{\mathrm{h}} \equiv W_{\mathrm{h}} / \sqrt{V_{\mathrm{h}}}$ and $\varphi_{1} \equiv W_{1} / \sqrt{V_{1}}$.

\section{Appendix B: Estimating default probability and default correlation}

We adopt the method of calculating average cumulative default rates with adjustment for rating withdrawals used by Moody's, as demonstrated by Cantor and Hamilton (2007).

A cumulative default rate for an investment horizon of length $T$, denoted as $D(T)$ is formulated 


$$
\begin{aligned}
D_{y}(T)= & d_{y}(1)+d_{y}(2)\left[1-d_{y}(1)\right]+d_{y}(3)\left[\left(1-d_{y}(1)\right)\left(1-d_{y}(2)\right)\right]+\ldots \\
& +d_{y}(T)\left(\prod_{t=1}^{T-1}\left[1-d_{y}(t)\right]\right)=1-\prod_{t=1}^{T}\left[1-d_{y}(t)\right]
\end{aligned}
$$

where $d_{y}(t)$ is the marginal default rate in the time interval $t^{21}$ for a cohort of issuers formed on date $y$ holding a certain rating and calculated as $d_{y}(t)=\frac{x_{y}(t)}{n_{y}(t)}$, where $x$ is the number of defaults and $n$ is the effective size of the cohort adjusted for rating withdrawals. As displayed, the cumulative default rate is essentially a discrete-time approximation of the nonparametric continuous-time-hazard-rate approach and a conditional probability.

We adopt average cumulative default rates, where the average is taken over many cohort periods, to estimate default probabilities in our study. The average cumulative default rate for an investment horizon of length $T$, denoted as $\bar{D}(T)$, is derived from the weighted average marginal default rates, $\bar{d}(t)$, where the average is taken over all the available cohort marginal default rates in the historical data set $Y$.

Then $\bar{D}(T)=1-\prod_{t=1}^{T}[1-\bar{d}(t)]$, where $\bar{d}(t)=\frac{\sum_{y \in Y} x_{y}(t)}{\sum_{y \in Y} n_{y}(t)}$.

As we estimate the default correlations, we modify the above methodology accordingly.

The pair-wise default probability, for one corporation with rating 1 and another with rating 2 in the time interval $t$, is $\frac{x_{y}^{1}(t) x_{y}^{2}(t)}{n_{y}^{1}(t) n_{y}^{2}(t)}$, where $x_{y}^{1}$ and $x_{y}^{2}$ are the numbers of defaults for cohorts of issuers holding rating 1 and 2 formed on date $y$ respectively, and $n_{y}^{1}$ and $n_{y}^{2}$ are the corresponding effective sizes of the cohorts. Then, the average pair-wise default rate in the time interval $t$ over all available cohorts is $\overline{d_{12}}(t)=\frac{\sum_{y \in Y} x_{y}^{1}(t) x_{y}^{2}(t)}{\sum_{y \in Y} n_{y}^{1}(t) n_{y}^{2}(t)}$.

\footnotetext{
${ }^{21}$ For example, in the first period after the formation of a cohort, $t=1$; in the second period after the formation of a cohort, $t=2$; etc.
} 
Hence, we could estimate the default correlation for the investment horizon of length $T$ by an average over all available marginal default correlations in the data set $Y$ :

$$
\bar{\rho}_{12}(T)=\frac{1}{T-1} \sum_{t=1}^{T-1} \rho_{12}(t),
$$

where $\rho_{12}(t)$ is the marginal default correlation in the time interval $t$, averaged over all available cohorts: ${ }^{22}$

$$
\rho_{12}(t)=\frac{\bar{d}_{12}(t)-\bar{d}_{1}(t) \bar{d}_{2}(t)}{\sqrt{\bar{d}_{1}(t)\left[1-\bar{d}_{1}(t)\right] \bar{d}_{2}(t)\left[1-\bar{d}_{2}(t)\right]}} .
$$

\section{References}

Altman, E. I. (1993). Corporate Financial Distress and Bankruptcy. Wiley, New York.

Altman, E. I., Rijken, H., Watt, M., Balan, D., Forero, J., and Mina, J. (2010). The Z-metrics(TM) methodology for estimating company credit ratings and default risk probabilities. The RiskMetrics Group, June.

Altman, E. I., and Saunders, A. (1998). Credit risk measurement: Developments over the last 20 years. Journal of Banking and Finance, 21, 1721-1742.

Basel Committee on Banking Supervision (1998). International convergence of capital measurement and capital standards. Bank for International Settlements, Basel.

Basel Committee on Banking Supervision (2004). International convergence of capital measurement and capital standards: A revised framework. Bank for International Settlements, Basel.

\footnotetext{
${ }^{22} \rho_{12}(T)$ is excluded in the calculation of $\bar{\rho}_{12}(T)$ because there is only one observation at $T$ resulting from one cohort left with a certain rating, which results in zero correlation.
} 
Basel Committee on Banking Supervision (2010). Basel III: A global regulatory framework for more resilient banks and banking systems. Bank for International Settlements, Basel.

Bawa, V. S., and Lindenberg, E. B. (1977). Capital market equilibrium in a mean-lower partial moment framework. Journal of Financial Economics, 5, 189-200.

Behn, M., Haselmann, R., and Wachtel, P. (2016). Procyclical capital regulation and lending. Journal of Finance, 71, 919-956.

Berger, A. N., and Udell, G. F. (2004). The institutional memory hypothesis and the procyclicality of bank lending behavior. Journal of Financial Intermediation, 13, 458-495.

Cantor, R., and Hamilton, D. T. (2007). Adjusting corporate default rates for rating withdrawals. Journal of Credit Risk, 3, 3-25.

Choi, D. B., Holcomb, M. R., and Morgan, D. P. (2018). Bank leverage limits and regulatory arbitrage: new evidence on a recurring question. Federal Reserve Bank of New York Staff Report, 856.

Crouhy, M., Galai, D., and Mark, R. (2000). A comparative analysis of current credit risk models. Journal of Banking and Finance, 24, 59-117.

DeAngelo, H., and Stulz, R. M. (2015). Liquid-claim production, risk management, and bank capital structure: Why high leverage is optimal for banks. Journal of Financial Economics, 116, 219-236.

Deloitte (2014). U.S. regulatory capital: Basel III supplementary leverage ratio final rule. Key highlights for advanced approaches banks. Deloitte Development LLC. 
Duchin, R., and Sosyura, D. (2012). The politics of government investment. Journal of Financial Economics, 106, 24-48.

Duffie, D., and Singleton, K. J. (2003). Credit risk: Pricing, measurement, and management. Princeton, NJ: Princeton University Press.

Furfine, C. (2001). Bank portfolio allocation: The impact of capital requirements, regulatory monitoring, and economic conditions. Journal of Financial Services Research, 20, 33-56.

Furlong, F. T., and Keeley, M. C. (1989). Capital regulation and bank risk-taking: A note. Journal of Banking and Finance, 13, 883-891.

Gordy, M. B. (2000). A comparative anatomy of credit risk models. Journal of Banking and Finance, 24, 119-149.

Kealhofer, S., and Bohn, J. R. (2001). Portfolio management of default risk. KMV LLC, San Francisco, CA.

Kim, D., and Santomero, A. M. (1988). Risk in banking and capital regulation. Journal of Finance, $43,1219-1233$.

Koehn, M., and Santomero, A. M. (1980). Regulation of bank capital and portfolio risk. Journal of Finance, 35, 1235-1244.

Li, L. (2013). TARP funds distribution and bank loan supply. Journal of Banking and Finance, 37, $4777-4792$.

Markowitz, H. (1952). Portfolio selection. Journal of Finance, 7, 77-91. 
Mencía, J. (2012). Assessing the risk-return trade-off in loan portfolios. Journal of Banking and Finance, 36, 1665-1677.

Milne, A. (2002). Bank capital regulation as an incentive mechanism: Implications for portfolio choice. Journal of Banking and Finance, 26, 1-23.

Murfin, J. (2012). The supply-side determinants of loan contract strictness. Journal of Finance, 67, $1565-1601$.

Papke, L. E., and Wooldridge, J. M. (2008). Panel data methods for fractional response variables with an application to test pass rates. Journal of Econometrics, 145, 121-133.

Repullo, R., and Suarez, J. (2013). The procyclical effects of bank capital regulation. Review of Financial Studies, 26, 452-490.

Rochet, J.-C. (1992). Capital requirements and the behaviour of commercial banks. European Economic Review, 36, 1137-1178.

Santos, J. A. C., and Winton, A. (2008). Bank loans, bonds, and informational monopolies across the business cycle. Journal of Finance, 63, 1315-1359.

Sharpe, W. F. (1966). Mutual fund performance. Journal of Business, 39, 119-138.

Tobin, J. (1958). Liquidity preference as a behavior towards risk. Review of Economic Studies, 25, $65-86$.

Treasury, the Federal Reserve System, and Federal Deposit Insurance Corporation (2007). Risk-based capital standards: Advanced capital adequacy framework-Basel II. Rules and Regulations, Federal Register, Washington. 
Treasury, the Federal Reserve System, and Federal Deposit Insurance Corporation (2008). Risk-based capital guidelines; Capital adequacy guidelines: Standardized framework. Proposed Rules, Federal Register, Washington.

VanHoose, D. (2007). Theories of bank behavior under capital regulation. Journal of Banking and Finance, 31, 3680-3697.

Volcker, P. (1987). Testimony to Congress. Federal Reserve Bulletin, June, 435-440. 